Diabetologia 9, 294-298(1973)

0 by Springer-Verlag 1973

\title{
Effects of Parabiosis of Obese with Diabetes and Normal Mice*
}

\author{
D.L. Coleman \\ The Jackson Laboratory** Bar Harbor, Maine 04609, USA \\ Received: March 1, 1973, accepted: April 10, 1973
}

\begin{abstract}
Summary. Parabiosis of obese (ob/ob) with diabetes $\left(d b^{2 J} / d b^{2 J}\right)$ mice caused the obese partner to become hypoglycemic, to lose weight and to die of starvation, while no abnormal changes were observed in the diabetes partner. The striking similarity of this response to that observed in normal mice in parabiosis with diabetes mice suggests that obese mice are like normal mice in having normal satiety centers sensitive to the satiety factor produced by the diabetes partner. In contrast, parabiosis of obese with normal mice is a fully viable combination suggesting that the obese partner does not produce sufficient satiety factor to turn off the normal partner's eating drive. However, obese mice in parabiosis with normal mice gain weight less rapidly and eat less than obese mice in para-
\end{abstract}

biosis with obese mice. These observations suggest that some humoral factor is provided by the normal partner that regulates food consumption in the obese partner. To explain the identical obese-hyperylycemic syndromes produced by these two unrelated and separate genes when on identical genetic backgrounds, it is postulated that the obese mouse is unable to produce sufficient satiety factor to regulate its food consumption, whereas the diabetes mouse produces satiety factor, but cannot respond to it because of a defective satiety center.

Key words: Parabiosis, obese mice, diabetes mice, satiety factor, satiety center.
The obesity-diabetic syndrome in mice caused by the gene, obese $(o b)$, located in chromosome 6 , is similar to that caused by the gene, diabetes $(d b$ and $d b^{2 J}$ ), located in chromosome 4 . Both syndromes are characterized by hyperphagia, obesity, hyperglycemia and hyperinsulinemia, associated with characteristic pancreatic changes. Recently it was established that the genetic background on which these two genes are maintained markedly influences their expression $[4,7]$. Diabetes and obese on the C57BL/6J background produce seemingly identical syndromes characterized by obesity, mild diabetes with moderate hyperglycemia, and markedly elevated plasma insulin concentrations, associated with hypertrophy and hyperplasia of the islets of Langerhans. In contrast, both genes on the C57BL/KsJ background produce obesity, severe diabetes with marked hyperglycemia and transient hyperinsulinemia, associated with atrophy of the islets of Langerhans. The islet response, whether atrophy or hypertrophy, is basic to the subsequent clinical development of the syndrome and appears not to be a consequence of the specific gene, but rather is due to the interaction of obese or diabetes with unknown modifying genes in the genetic background. Islet atrophy, not unexpectedly, results in decreased plasma insulin, marked hyperglycemia, and premature death, whereas islet hypertrophy is associated with a nearly normal lifespan and markedly elevated plasma insulin con-

* Supported in part by NIH. Research Grant AM 14461 from the National Institute of Arthritis, Metabol. ism, and Digestive Diseases and by an allocation from the South Waite Foundation.

** The Jackson Laboratory is fully accredited by the American Association for Accreditation of Laboratory Animal Care. centrations, sufficient to reduce blood sugar to near normal.

The availability of strains of mice carrying these two genes on the same two genetic backgrounds has allowed eritical comparisons of the development of the syndromes caused by each gene on each background. No differences have been found with respect to rate of weight gain, lifespan, islet morphology and blood levels of insulin and glucose $[4,7]$. Since these two genes in separate chromosomes cause seemingly identical syn. dromes, the implication is that the deviations from normal observed in all of these parameters are second. ary to the, as yet, unidentified primary defects.

The only difference in the expression of the two genes, which cannot be ascribed to the effect of background genotype, occurs when these mutant mice are parabiosed to normal $(+1+)$ mice. When parabiont pairs of diabetes with normal mice were produced [3], it was observed that the normal partners rapidly lost weight, became hypoglycemic and died of apparent starvation within 50 days after surgery, whereas no abnormal changes were observed in the diabetic partners. From these results it was postulated that the diabetes mutant produces, but does not respond to, a satiety factor which is transported to the satiety center of the normal partner, where it completely shuts off the normal partner's eating drive. Studies by others $[1,5,6]$ demonstrated that parabiosis of obese $(o b / o b)$ with normal mice did not result in starvation and death of the normal partner. Instead, the rate of weight gain of the obese mouse was suppressed and, in some cases, gains beyond pre-union levels did not occur [6]. After separation, the obese partners again gained weight rapidly, suggesting that some factor transmitted in parabiosis is missing in obese mice. 
The development of the C57BL/6J-db $2 J$ stain [7] of diabetes mice, congenic with the $\mathrm{C} 57 \mathrm{BL} / 6 \mathrm{~J}-o b$ strain of obese mice, permitted unions between obese and diabetes mice for comparison with "obese with normal" and "diabetes with normal" parabiont pairs. Previous studies (Coleman, unpublished) have demonstrated that parabiosis of diabetes mice of strain $\mathrm{C} 57 \mathrm{BL} / 6 \mathrm{~J}$. $d b^{2 J}$ with normal strain $\mathrm{C} 57 \mathrm{BL} / 6 \mathrm{~J}$ mice results in death of the normal partner from starvation in an identical fashion to that reported for diabetes mice of strain $\mathrm{C} 57 \mathrm{BL} / \mathrm{KsJ}_{-} d b$ with normal $\mathrm{C} 57 \mathrm{BL} / \mathrm{K}_{\mathrm{sJ}}$ mice [3]. These results clearly establish that the death of the normal partner is a specific effect of the diabetes gene rather than an association with the inbred background in which it is maintained.

\section{Materials and Methods}

Obese mice $(o b / o b)$ of strain $\mathrm{C} 57 \mathrm{BL} / 6 \mathrm{~J}-o b$ and normal C57BL/6J controls were procured from the Jackson Laboratory Production Department. Diabetes mice $\left(d b^{2 J} / d b^{2 J}\right)$ of strain $\mathrm{C} 57 \mathrm{BL} / 6 J-d b^{2 J}$ were obtained from a mutant research colony maintained at the Jackson Laboratory. All mice were fed a commercial laboratory chow (Old Guilford, Guilford, Conn.) containing 6\% of fat.

Parabiosis was performed when mice were between 6 and 8 weeks of age. The technique of parabiosis was as previously described [3] and included celioanastomosis as well as anastomosis of the skin from the shoulder to the pelvic girdle. After surgery each parabiont pair was housed separately and given food and water ad libitum. The parabiont pairs were observed daily to obtain survival data and to establish which partner of the pair died first.

Four groups of parabiont pairs were produced: group $1, a b / o b$ with normal $(+/+)$; group $2, o b / o b$ with $d b^{25} / d b^{2 J}$; group $3, o b / o b$ with $o b / o b$; and group $4,+1+$ with $+/+$. Group 5 consisted of 10 obese $(o b / o b)$ unparabiosed controls. Weights of pairs and single controls were recorded weekly at the same time that blood sugar concentrations were determined on each animal of all groups. Plasma immunoreactive insulin concentrations were determined in both partners of a few of the pairs. All analytical determinations were as described previously [2].

Food consumption over a $24 \mathrm{~h}$ period was determined by providing a weighed amount of pelleted food each morning and weighing that remaining the following morning.

\section{Results}

Group 1 consisted of 15 obese $(o b / o b)$ with normal $(+1+)$ pairs. Of these 15 pairs, 2 died within three weeks after the surgery. Both partners in these 2 pairs had lost weight but in each case it was the normal that died first, as evidenced by the blood congestion in the liver, lungs, kidneys, and spleen. This blood congestion is always present in the partner dying first, since the surviving animal in the pair continues to pump blood into the dead partner until its own death. The remaining 13 pairs lived in apparent good health until they were killed 4 to 6 months after parabiosis. The weight changes and blood sugar concentrations of each mouse in these pairs (group 1) are shown in Table 1. Both partners gained weight during the period of the union, the obese partners gaining an average of $10.4 \mathrm{~g}$ while the normal partners gained an average of $3.0 \mathrm{~g}$. The blood sugar concentrations were slightly depressed in both partners at 3 weeks and at 3 months after parabiosis. Plasma insulin determinations were made on each animal in 8 of the pairs at 60 days. The average value for the obese partners $(150 \pm 21 \mu \mathrm{U} / \mathrm{ml})$ was markedly less than that for the 3 to 4 month old unparabiosed obese mice $(2740 \pm 197 \mu \mathrm{U} / \mathrm{ml})$. In contrast the average value for the normal partners (47.1 \pm $10.3 \mu \mathrm{U} / \mathrm{ml}$ ) was not substantially lower than that previously reported for unparabiosed normal mice $(60 \mu \mathrm{U})$ ml) $[2]$.

Group 2 consisted of 16 diabetes $\left(d b^{2 J} / d b^{2 J}\right)$ with obese $(o b / o b)$ pairs. Of these, 3 pairs died 8 days after the surgery. In all three cases the obese partner died first. Even though this was the typical pattern for this group of parabionts, such short survival may have represented poor surgical procedure rather than the response to parabiosis. Of the remaining 13 pairs, only one lived longer than 4 months. The diabetes partner in this union was markedly hyperglycemic (blood sugar $>400 \mathrm{mg} / 100 \mathrm{ml}$ ) throughout its entire life and was clearly not representative of diabetes mice on the C57BL/6J background. The data obtained from this pair are not included in Table 1.

Median survival time of the remaining 12 pairs of group 2 was 26 days and the survival times ranged from 13 to 90 days (Table 1). In all cases the obese $(o b / o b)$ partners died first after losing considerable weight (average loss, $14.9 \mathrm{~g}$ ) and becoming severely hypoglycemic. At 3 weeks the average blood sugar concentration was only $50 \%$ of the average starting value and only one-third of that observed in the control, unparabiosed obese mice (Group 5) 9-10 weeks of age. In addition to blood congestion in the tissues of the obese partner, autopsies revealed much smaller than normal livers, vastly decreased amounts of adipose tissue and little or no food in the digestive tracts. In contrast, the diabetes partners had all gained weight, had stomachs bulging with food and had the enlarged livers and adipose stores typical of these hyperphagic mutants. These observations suggest that the obese partner died of starvation as did normal mice in parabiosis with either $\mathrm{C} 57 \mathrm{BL} / \mathrm{Ks} J-d b / d b[3]$ or $\mathrm{C} 57 \mathrm{BL} / 6 \mathrm{~J}$ $d b^{2 J} / d b^{2 . J}$ mice (unpublished).

Group 3 consisted of 8 obese with obese pairs. Three pairs died within 2 weeks after surgery and probably reflected poor surgical technique. Since no data other than 
the starting weight was collected on these pairs, the data presented in Table 1 represent only 5 pairs. At sacrifice, after 4 months of parabiosis, all mice appeared to be healthy, had large fat stores and enlarged livers typical of obese $(o b / o b)$ mice. All gained weight during this period and their average weight at sacrifice was more than $50 \%$ above their average starting weight. Average blood sugar concentrations at the two periods shown in Table 1 were slightly elevated, but three weeks after surgery the average values were distinctly less than those observed for the unparabiosed obese mice of group 5. Plasma insulin concentrations ranged from 240 to $800 \mu \mathrm{U} / \mathrm{ml}$ at 60 days in both mice of the value of $17.8 \pm 2.3 \mu \mathrm{U} / \mathrm{ml}$ compared with $60 \mu \mathrm{U} / \mathrm{ml}$ for unparabiosed normal mice [2].

The 10 obese control mice of group 5 had clinical features similar to those previously reported $[4,7]$. During the period from 6 to 10 weeks of age, (comparable to the average survival time of obese mice in parabiosis with diabetes mice) an average increase in weight of over $12 \mathrm{~g}$ was recorded (Table 1). Blood sugar concentrations were elevated at 9 weeks and at 18 weeks had returned to near normal levels. Plasma insulin concentrations averaged $2740 \pm 197 \mu \mathrm{U} / \mathrm{ml}$ in the seven obese mice assayed. This value was distinctly higher than the average value for the obese partners

Table 1. Effect of parabiosis on average weight increase, blood sugar concentrations and median survival times in obese, diabetes, and normal mice

\begin{tabular}{|c|c|c|c|c|c|c|c|}
\hline \multirow{2}{*}{$\begin{array}{l}\text { Genotype } \\
\text { combination }\end{array}$} & \multirow{2}{*}{$\begin{array}{l}\text { Number } \\
\text { of } \\
\text { pairs }\end{array}$} & \multicolumn{2}{|l|}{ Weight (g) } & \multicolumn{3}{|c|}{ Blood sugar concentration (mg/100 ml) } & \multirow{2}{*}{$\begin{array}{l}\text { Median } \\
\text { survival time } \\
\text { (days) }\end{array}$} \\
\hline & & initial & at death & initial & $\begin{array}{l}\text { after parabic } \\
3 \text { weeks }\end{array}$ & 12 weeks & \\
\hline $\begin{array}{l}\text { 1. } o b / o b \text { with } \\
+/+\end{array}$ & 13 & $\begin{array}{l}29.4 \pm 0.9 \\
22.5 \pm 1.0\end{array}$ & $\begin{array}{l}39.8 \pm 2.0^{*} \\
25.5 \pm 1.3^{*}\end{array}$ & $\begin{array}{l}193 \pm 12.7 \\
150 \pm 5.8\end{array}$ & $\begin{array}{l}\mathbf{1 3 4} \pm 6.1^{*} \\
128 \pm 4.2^{*}\end{array}$ & $\begin{array}{l}137 \pm 6.2^{*} \\
120 \pm 7.5^{*}\end{array}$ & $>120$ \\
\hline $\begin{array}{l}\text { 2. } a b / o b \text { with } \\
d b^{2 J} / d b^{2 J}\end{array}$ & 12 & $\begin{array}{l}33.7 \pm 1.5 \\
30.3 \pm 1.5\end{array}$ & $\begin{array}{l}18.8 \pm 1.2^{*} \\
33.2 \pm 1.1\end{array}$ & $\begin{array}{l}185 \pm 9.9 \\
176 \pm 9.5\end{array}$ & $\begin{array}{c}94.2 \pm 7.1 * \\
180 \pm 14.9\end{array}$ & - & 26 \\
\hline $\begin{array}{l}\text { 3. ob/ob with } \\
o b / o b\end{array}$ & 5 & $\begin{array}{l}27.6 \pm 0.8 \\
26.6 \pm 1.2\end{array}$ & $\begin{array}{l}47.0 \pm 4.3^{*} \\
44.0 \pm 3.4^{*}\end{array}$ & $\begin{array}{l}180 \pm 21.7 \\
185 \pm 25.1\end{array}$ & $\begin{array}{l}184 \pm 21.7 \\
206 \pm 29.9\end{array}$ & $\begin{array}{l}191 \pm 22.1 \\
189 \pm 15.1\end{array}$ & $>120$ \\
\hline $\begin{array}{c}\text { 4. } \begin{array}{l}+1+\text { with } \\
+1+\end{array}\end{array}$ & 5 & $\begin{array}{l}20.3 \pm 1.2 \\
20.8 \pm 1.3\end{array}$ & $\begin{array}{l}23.6 \pm 1.9 \\
21.4 \pm 1.0\end{array}$ & $\begin{array}{l}148 \pm 5.3 \\
155 \pm 5.9\end{array}$ & $\begin{array}{l}136 \pm 6.8 \\
139 \pm 5.2\end{array}$ & $\begin{array}{l}123 \pm 5.2^{*} \\
116 \pm 3.6^{*}\end{array}$ & $>120$ \\
\hline 5. ob/ob (single) & 10 & $31.0 \pm 1.1^{\mathrm{a}}$ & $43.7 \pm 1.1 * b$ & $189 \pm 13.7$ & $251 \pm 19.5 *$ & $170 \pm 14.3$ & - \\
\hline
\end{tabular}

Figures represent average values \pm standard error of the mean.

Asterisks (*) indicate values significantly $(P<0.01)$ from starting values.

a 6 weeks of age.

b 10 weeks of age.

Table 2. Effect of parabiosis on daily food consumption and rate of weight gain in obese and normal mice

\begin{tabular}{|c|c|c|c|c|c|c|}
\hline \multirow{2}{*}{$\begin{array}{l}\text { Genotype } \\
\text { combination }\end{array}$} & \multirow{2}{*}{$\begin{array}{l}\text { Starting } \\
\text { weight }(g)\end{array}$} & \multicolumn{2}{|c|}{ Weight after parabiosis } & \multicolumn{2}{|c|}{ Weight gain } & \multirow{2}{*}{$\begin{array}{l}\text { Daily food } \\
\text { consumption }(\mathrm{g})\end{array}$} \\
\hline & & 4 weeks & 8 weeks & 4 weeks & 8 weeks & \\
\hline$o b / o b$ with $+/+$ & $52.9 \pm 1.8$ & $55.9 \pm 2.1$ & $61.2 \pm 2.5$ & 3.0 & 8.3 & $7.0 \pm 0.16$ \\
\hline$o b / o b$ with $o b / o b$ & $58.0 \pm 1.7$ & $78.5 \pm 3.0$ & $96.7 \pm 2.9$ & 20.5 & 38.7 & $9.2 \pm 0.19$ \\
\hline$+1+$ with $+1+$ & $48.4 \pm 1.0$ & $54.7 \pm 1.0$ & $56.6 \pm \mathbf{1 . 7}$ & 6.3 & 8.2 & $6.3 \pm 0.14$ \\
\hline
\end{tabular}

Figures represent average values per pair \pm standard error of the mean.

2 pairs tested. The average concentration $(635 \pm 146$ $\mu \mathrm{U} / \mathrm{ml})$ was considerably less than that observed. $(2740 \pm 197 \mu \mathrm{U} / \mathrm{ml})$ in 3 to 4 months old obese mice of groap 5 .

Six normal with normal parabiont pairs (group 4) were produced, of which one died before 21 days. The rest survived in a healthy state until they were sacrificed at 4 months of age. Average weight gain of each mouse was from 1 to $3 \mathrm{~g}$, an amount somewhat less than expected for normal mice not in parabiosis. Upon gross examination at autopsy, all tissues appeared to be normal. Blood sugar concentrations were slightly subnormal 3 weeks after parabiosis and were still below the normal range at 3 months (Table 1). Plasma insulin concentrations were reduced to an average
$(150 \pm 21 \mu \mathrm{U} / \mathrm{ml})$ of group 1 , as well as being higher than that for obese partners in group $3(635 \pm 146 \mu \mathrm{U} / \mathrm{ml})$.

Table 2 shows the average weights of 4 pairs of each of the 3 types of non-lethal parabiotic unions after 1 and 2 months of parabiosis. Since the mice were not killed at these times, it was not possible to establish the individual weight gain by each partner. However, it was apparent that both $+1+$ with $+1+$ and $o b / o b$ with $a b / o b$ pairs made substantial weight increases during the two-month period. From these figures a calculated weight increase was obtained for the $o b / o b$ with $+1+$ pairs by adding the average weight gain of the $+1+$ with $+1+$ pairs to that of the $o b / o b$ with $o b / o b$ pairs and dividing by 2 . This calculation gave values of $13.4 \mathrm{~g}$ at 4 weeks and 23.5 at 8 weeks for 
the weight gain of an "ideal" $o b / o b$ with $+1+$ pair. These values are in distinct contrast to those actually obtained (3.0 and $8.3 \mathrm{~g}$ ). This marked discrepancy suggests that some factor is operating in the $o b / o b$ with $+1+$ pairs to prevent the expected weight gain.

The average weights of the individual normal and obese parabionts of group 1 at sacrifice show that both the normal and obese partners in these pairs gained weight during this longer period of parabiosis (Table 1). However, whereas the average weight gain by the normal partners in this group was comparable to that of the normal with normal parabionts of group 4, the average weight gain $(10.4 \mathrm{~g})$ by the obese partners was substantially less than that (18.4 g) observed in the obese with obese parabionts of group 3 . This suggests that the less than anticipated weight increases of the obese with normal pairs represent subnormal weight gains by the obese partners that can be attributed to the presence of their normal partners. Food consumption records obtained on 4 pairs of each type of union at weekly intervals from the third to sixth week after parabiosis indicate that the subnormal weight gains by the obese partners were most likely due to decreased food consumption (Table 2). Average food consumption of the obese with normal pairs ranged from a low of $6.2 \mathrm{~g}$ per day to $7.9 \mathrm{~g}$ per day during the 4 week period of study, whereas that for the normal with normal pairs during the same period was less and ranged from 5.4 to $7.0 \mathrm{~g}$ per day. Average food consumption of the obese with obese pairs was higher and ranged from 7.6 to $10.5 \mathrm{~g}$ per day. Adding the average food consumption of the normal with normal pairs $(6.3 \mathrm{~g} /$ day $)$ to that of the obese with obese pairs ( $9.2 \mathrm{~g} /$ day) and dividing by 2 gives a calculated food consumption of $7.75 \mathrm{~g}$ per day for an "ideal" obese with normal parabiont pair, compared with the smaller actual value of $7.0 \mathrm{~g}$ per day (Table 2).

\section{Discussion}

Parabiosis of obese with diabetes mice caused the obese partner to become hypoglycemic, to lose weight, and to die of apparent starvation once its tissue reserves were exhausted. The striking similarity of the pattern of this response to that observed when normal mice were in parabiosis with diabetes mice [3] suggests that a similar mechanism is operative and that obese mice are like normal mice with normal satiety centers sensitive to a satiety factor produced by the diabetes partners. The observation that the parabiosis of obese with normal mice is a completely viable combination is in agreement with the results of others $[1,5,6]$. Since this combination is not lethal to the normal partners, one must conclude that obese mice do not produce sufficient satiety factor to effectively turn off the normal partner's eating drive. It may be that obese mice are unable to produce satiety factor or that, in parabiosis with normal mice, they respond to some factor pro- duced by the normal that prevents production of satiety factor. The much less than expected weight gain observed in the obese partner coupled with marked decreases in both plasma insulin and blood sugar concentrations suggests that a humoral factor regulates these parameters, either directly or indirectly, by decreasing the amount of food consumed.

This suggestion is supported by the food consumption data obtained in these studies. The average food consumption of the obese with normal pairs was $0.75 \mathrm{~g} /$ day less than that calculated for an "ideal" obese with normal pair. Whether this observed decrease in food consumption for the pair was sufficient, in itself, to account for the entire decreased weight gain of the obese partner in the obese with normal pairs is difficult to establish. The different combinations of parabiotic unions result in varying levels of spontaneous activity ranging from very low for obese with obese parabionts to high for normal with normal parabionts. The enforced, increased activity of the obese mouse when in parabiosis with a more active normal mouse has been suggested by Chlouverakis [1] to contribute to the less than expected weight gain. The extent of this contribution in the present studies is unknown.

The suggestion that some factor is missing in the obese mouse that can be supplied by successful parabiosis with a normal animal was originally made by Hausberger [6]. Support for the existence of a humoral factor comes from studies by Strautz [8] in which isolated islets from normal mice were placed in millipore chambers in the peritoneal cavities of obese mice. These preparations prevented further weight increases and decreased the blood sugar and plasma insulin concentrations to within normal limits. Islets isolated from obese mice were without effect. The identity of this islet factor and its mode of action have not been established, but it seems likely that the same factor may be involved in Strautz's studies and in those dealing with obese and normal mice in parabiosis. Data presented here suggest that the factor is involved in regulating food consumption in obese mice.

The fact that two of the obese with normal pairs died within three weeks, with the normal partner $\mathrm{dy}$ ing first, suggests that in some cases the obese with normal combination may be lethal. Also, the observations of Chlouverakis [1] that there is a high mortality rate in obese with normal unions and of Haessler and Crawford [5] that the obese partner, in some cases, parasitizes the normal are consistent with detrimental effects of such unions.

An explanation consistent with the data presented here and that found in publications by others is that diabetes mice produce, but do not respond to, a satiety factor that normally regulates food consumption. This conclusion is supported by the lethal nature of parabiotic unions of diabetes with either normal or obese mice. Since obese mice in parabiosis with diabetes mice respond like normal mice it can be concluded that the obese mice have normal satiety centers 
sensitive to the saticty factor produced by the diabetes partner. Since obese with normal parabiotic unions are viable, this suggests that obese mice do not produce sufficient satiety (lethal) factor to turn off the normal partner's eating drive. However, the obese partners in such unions gained less weight and ate less than obese mice in parabiosis with obese mice suggesting that some humoral factor is provided by the normal that regulates food consumption in the obese partner. These observations provide further support for the conclusion that the obese mouse has a functional satiety center and that it is capable of responding to satiety factor produced by normal as well as diabetes partners. If these conclusions are correct, the identical obese-hyperglycemic syndromes produced by these two unrelated and separate genes would be explained. In one case, the target organ (satiety center) is defective while in the other the satiety factor is either not produced or is produced in insufficient quantities. Both mechanisms would cause over-eating and produce identical secondary changes in both obese and diabetes mice.

Acknowledgements. The skilled technical assistance of Miss Dorothy M. Jahoda and Mr. R.H. Copp is gratefully acknowledged.

\section{References}

1. Chlouverakis, C.: Insulin resistance of parabiotic obeseobob. Horm. Metab. Res. 4, 143-148 (1972).

2. Coleman, D. L., Hummel, K.P. : Studies with the mutation, diabetes, in the mouse. Diabetologia 3, 238-248 (1967).

3. Coleman, D.L., Hummel, K.P.: Effocts of parabiosis of normal with genotically diabetic mice. Amer. $\mathbf{J}$. Physiol. 217, 1298-1304 (1969).

4. Coleman, D.L., Hummel, K.P.: The influence of genetic background on the expression of the obese $(o b)$ gene in the mouse. Diabetologia, 9, $287-293$ (1973).

5. Haessler, H. A., Crawford, J. D. : Alterations in the fatty acid composition of depot fat associated with obesity. Ann. N. Y. Acad. Sei. 131, 476 $\cdots 48$ (1965).

6. Hausberger, F.X.: Parabiosis and transplantation experiments in hereditary obese mice. Anat. Rec. 130, 313 abstr. (1958).

7. Hummel, K.P., Coleman, D.L., Lane, P.W.: The influence of genetic background on expression of mutations at the diabetes locus in the mouse. Biochem. Genet. 7, 1-13 (1972).

8. Strautz, R.L.: Studies of hereditary-obese mice (obob) after implantation of pancreatic islets in millipore filter capsules. Diabetologia 6, 306-312 (1970).

Dr. D.L. Coleman

The Jackson Laboratory

Bar Harbor

Maine 04609

USA 